\title{
Liposomal $n$-butylidenephthalide protects the drug from oxidation and enhances its antitumor effects in glioblastoma multiforme
}

This article was published in the following Dove Press journal:

International Journal of Nanomedicine

28 September 2015

Number of times this article has been viewed

\author{
Yu-Ling Lin ${ }^{1,2, *}$ \\ Kai-Fu Chang ${ }^{3, *}$ \\ Xiao-Fan Huang ${ }^{3}$ \\ Che-Lun Hung ${ }^{4}$ \\ Shyh-Chang Chen ${ }^{5}$ \\ Wan-Ru Chao ${ }^{6,7}$ \\ Kuang-Wen Liao ${ }^{1,8}$ \\ Nu-Man Tsai ${ }^{3,9}$ \\ 'College of Biological Science \\ and Technology, ${ }^{2}$ Center for \\ Bioinformatics Research, National \\ Chiao Tung University, Hsinchu, \\ ${ }^{3}$ School of Medical Laboratory and \\ Biotechnology, Chung Shan Medical \\ University, ${ }^{4}$ Department of Computer \\ Science and Communication \\ Engineering, Providence University, \\ ${ }^{5}$ Department of Pathology and \\ Laboratory Medicine, Taichung \\ Veterans General Hospital, \\ ${ }^{6}$ Institute of Medicine, Chung Shan \\ Medical University, ${ }^{7}$ Department \\ of Pathology, Chung Shan Medical \\ University and Chung Shan Medical \\ University Hospital, Taichung, \\ ${ }^{8}$ Institute of Molecular Medicine \\ and Bioengineering, National Chiao \\ Tung University, Hsinchu, ${ }^{9} \mathrm{Clinical}$ \\ Laboratory, Chung Shan Medical \\ University Hospital, Taichung, Taiwan \\ *These authors contributed equally \\ to this work
}

Correspondence: Nu-Man Tsai School of Medical Laboratory and Biotechnology, Chung Shan Medical University, No II0, Section I, Jianguo North Road, Taichung 4020I, Taiwan

Tel +886 424730022 ext I24I I

Fax +886 42324 8I7I

Email numan@csmu.edu.tw
Background: The natural compound $n$-butylidenephthalide (BP) can pass through the bloodbrain barrier to inhibit the growth of glioblastoma multiforme tumors. However, BP has an unstable structure that reduces its antitumor activity and half-life in vivo.

Objective: The aim of this study is to design a drug delivery system to encapsulate BP to enhance its efficacy by improving its protection and delivery.

Methods: To protect its structural stability against protein-rich and peroxide solutions, BP was encapsulated into a lipo-PEG-PEI complex (LPPC). Then, the cytotoxicity of BP/LPPC following preincubation in protein-rich, acid/alkaline, and peroxide solutions was analyzed by MTT. Cell uptake of BP/LPPC was also measured by confocal microscopy. The therapeutic effects of BP/LPPC were analyzed in xenograft mice following intratumoral and intravenous injections.

Results: When BP was encapsulated in LPPC, its cytotoxicity was maintained following preincubation in protein-rich, acid/alkaline, and peroxide solutions. The cytotoxic activity of encapsulated BP was higher than that of free BP ( 4.5- to 8.5-fold). This increased cytotoxic activity of BP/LPPC is attributable to its rapid transport across the cell membrane. In an animal study, a subcutaneously xenografted glioblastoma multiforme mouse that was treated with BP by intratumoral and intravenous administration showed inhibited tumor growth. The same dose of BP/LPPC was significantly more effective in terms of tumor inhibition.

Conclusion: LPPC encapsulation technology is able to protect BP's structural stability and enhance its antitumor effects, thus providing a better tool for use in cancer therapy.

Keywords: $n$-butylidenephthalide, lipo-PEG-PEI complex, glioblastoma multiforme, antitumor

\section{Background}

The natural compound $n$-butylidenephthalide (BP), isolated from the chloroform extract of Angelica sinensis, has been reported to have antitumor activity in glioblastoma multiforme (GBM), ${ }^{1-4}$ prostate cancer, ${ }^{5,6}$ oral squamous cell carcinoma, ${ }^{7}$ lung cancer, ${ }^{8}$ and hepatoma. ${ }^{9}$ In particular, BP has been developed to treat brain tumors due to its ability to permeate through the blood-brain barrier and enter into the brain. ${ }^{1}$ BP induces Nur77-mediated apoptosis via the protein kinase C/JNK pathway. 4,7,9,10 BP downregulates the expression of S-phase kinase-associated protein (Skp2), which leads to an increase in p16 and p21 expression, causing $G_{0} / G_{1}$ arrest. ${ }^{2}$ BP inhibits telomerase activity by repressing hTERT transcriptional activity via the downregulation of Sp1 or AP-2 expression. ${ }^{3,8} \mathrm{BP}$ also regulates the eFAS-dependent pathway, the mitochondrial pathway, and the ER stress pathway that is involved in cell apoptosis. . $^{5,6}$ $\mathrm{BP}$ regulates multiple signaling pathways and possesses several therapeutic benefits, 
including antiangiogenic, ${ }^{11}$ anti-inflammatory, ${ }^{12,13}$ and antioxidant properties. ${ }^{12}$ However, the clinical application of BP is limited due to several problems. For instance, the unstable structure of BP in oxygenic environments causes a loss of its cytotoxicity. In addition, the water insolubility of BP leads to low bioavailability and poor pharmacokinetics in vivo. Its nonspecific distribution throughout the body when administered intravenously also limits its application. To protect the structure of BP during administration and to increase its aqueous solubility/dispersibility, a drug delivery system must be developed for BP encapsulation and treatment.

Currently, various nanoparticles, especially polymerbased liposomes, have been developed to encapsulate antitumor drugs, which can enhance their therapeutic efficacy. ${ }^{14}$ We recently reported the development of a polycationic liposome complex containing PEI and PEG (lipo-PEG-PEI complex [LPPC]) that can encapsulate curcumin and enhance its cytotoxicity. ${ }^{14,15}$ LPPC helped curcumin rapidly traverse the cell membrane and enabled its delivery into tumor areas to inhibit tumor growth in tumor-bearing mice. ${ }^{14}$ LPPC has also been used as an adjuvant because it can strongly capture antigens or immunomodulators onto its surface, which allows it to enhance or switch immune responses. ${ }^{16}$ These results therefore suggest that LPPC may serve as an effective drug carrier and a useful anticancer tool.

In this study, LPPC was used as a drug carrier to encapsulate BP for drug delivery. LPPC protected BP's structure and cytotoxicity against protein-rich and peroxide solutions. Furthermore, BP encapsulated into LPPC had higher cytotoxic activity than free BP. This increased cytotoxic activity of BP/LPPC was attributable to its rapid transport across the cell membrane. In an animal study, a xenograft GBM mouse was treated with BP/LPPC by intratumoral and intravenous (IV) administration, and BP/LPPC inhibited the growth of subcutaneous GBM tumors. Therefore, LPPC encapsulation technology is able to protect BP's structural stability and enhance its antitumor effects, providing a better tool for use in cancer therapy. Our Institutional Review Board does not require ethical approval for these types of studies.

\section{Materials and methods Preparation of LPPC and encapsulation of BP in LPPCs or liposomes}

LPPCs were prepared according to a previously described protocol. ${ }^{15}$ For BP/LPPC preparation, different volume ratios of $1 \mathrm{mM}$ BP (Lancaster Synthesis Ltd, Newgate, Morecambe, UK) and $1 \mathrm{mg}$ of LPPC were vigorously mixed for 15 seconds and incubated for 15 minutes. This procedure was conducted twice. After incubation, the mixture of BP and LPPC was centrifuged at $5,900 \times g$ for 5 minutes to remove free BP. The concentration of BP remaining in the supernatant was then measured using a fluorescence spectrophotometer (F-4500; Hitachi Ltd., Tokyo, Japan) with an excitation wavelength of $350 \mathrm{~nm}$ and an emission wavelength of $430 \mathrm{~nm}$. The particle size and zeta potential of BP/LPPC and empty LPPC particles were determined by a Zetasizer instrument (Zetasizer 3000HS; Malvern Instruments, Malvern, UK). BP liposomes devoid of PEI and PEG were prepared as described earlier. Briefly, $50 \mathrm{mg}$ DOPC and $50 \mathrm{mg}$ DLPC with $5 \mathrm{mg}$ BP in chloroform were mixed and were coated onto a round-bottom flask by a rotary evaporator (EYELA, N-1000S, Tokyo, Japan) to yield BP liposomes. The lipid films containing BP were hydrated by steam for 2 hours and then $5 \mathrm{~mL}$ of $\mathrm{ddH}_{2} \mathrm{O}$ was added into the container. The BP/lipid films were vigorously resuspended for 10 minutes, and the suspension was extruded through a LiposoFast extruder (Avestin Inc., Ottawa, Canada) via a 200-nm mesh nine times to give the correct particle size.

\section{In vitro drug release from BP/LPPC}

BP/LPPCs were suspended in $1 \mathrm{~mL}$ of phosphate-buffered saline (PBS; pH 7.4). Following this, the BP/LPPC solution was placed into a dialysis bag (Spectra/Por; Spectrum Laboratories Inc., Rancho Dominguez, CA, USA) with a 6-8 kDa molecular weight cutoff and immersed into $20 \mathrm{~mL}$ of PBS at $4^{\circ} \mathrm{C}, 25^{\circ} \mathrm{C}$, or $37^{\circ} \mathrm{C}$ with continuous stirring. In addition, to mimic the release of drug in circulation, the $\mathrm{BP} / \mathrm{LPPC}$ solution in the dialysis bag was submerged in a protein-rich solution (10\% fetal bovine serum [FBS; Thermo Fisher Scientific, Waltham, MA, USA] in PBS) at $37^{\circ} \mathrm{C}$. One-milliliter samples were collected from the incubation media at different time intervals, and the BP concentrations in the samples were measured as described earlier. The release rate was calculated as follows:

Release rate $(\%)=\frac{(\text { Released BP }) \text { amount }}{(\text { Total BP in LPPC }) \text { amount }} \times 100 \%$

\section{Cells and culture conditions}

GBM tumor cell lines and normal cell lines were purchased from Bioresources Collection and Research Center (Hsinchu, Taiwan). Four human GBM cell lines, DBTRG-05MG, G5T/TGH, GBM8401, and GBM8901 and the N18 mouse neuroblastoma cell line were cultured in RPMI-1640 (Thermo Fisher Scientific) growth media supplemented with 10\% heat-inactivated FBS (Thermo Fisher Scientific), 1\% sodium pyruvate (Thermo Fisher Scientific), 
1\% HEPES buffer solution (Thermo Fisher Scientific), and $1 \%$ penicillin/streptomycin (Thermo Fisher Scientific). RG2 rat GBM cells, SVEC mouse endothelial cells, and MDCK dog normal kidney cells were cultured in Dulbecco's Modified Eagle's Medium (Thermo Fisher Scientific) growth media supplemented with 10\% heatinactivated FBS (Thermo Fisher Scientific), 1\% sodium pyruvate (Thermo Fisher Scientific), 1\% HEPES buffer solution (Thermo Fisher Scientific), and 1\% penicillin/ streptomycin (Thermo Fisher Scientific). All cell lines were cultured in a humidified atmosphere of $5 \% \mathrm{CO}_{2}$ at $37^{\circ} \mathrm{C}$. The cells were subcultured using an enzymatic procedure (0.1\% trypsin, $2 \mathrm{mM}$ EDTA solution).

\section{Cytotoxicity of BP/LPPC}

The different cell lines were seeded into 96-well tissue culture plates at a concentration of $5 \times 10^{3}$ cells $/ 100 \mu \mathrm{L} /$ well and were allowed to grow overnight. The cells were subsequently treated with serial dilutions of the various agents, namely empty LPPC, BP/LPPC, and BP. After 48 hours of incubation, the cell viability of each cell line was determined by an MTT colorimetric assay. Briefly, $100 \mu \mathrm{L}$ of $2 \mathrm{mg} / \mathrm{mL}$ MTT reagent (Sigma-Aldrich, St Louis, MO, USA) was added to each well, and the solution was allowed to incubate for 4 hours at $37^{\circ} \mathrm{C}$. Then, the media was aspirated, and $100 \mu \mathrm{L}$ of dimethyl sulfoxide was added to each well. Finally, the $\mathrm{OD}_{595}$ of each well was measured by an ELISA reader (TECAN, Austria). Cell viability was plotted as a percentage of the untreated control, and the $50 \%$ inhibitory concentration $\left(\mathrm{IC}_{50}\right)$ of each reagent was determined from the dose-effect curve. Specifically, this was the drug concentration that decreased the cell viability to $50 \%$. The following equation was used to calculate the enhancement in cytotoxicity when using the encapsulated form of BP compared with the nonencapsulated form:

$$
\text { Enhanced toxicity }(\text { fold })=\frac{(\text { Nonencapsulated BP })_{\mathrm{IC}_{50}}}{(\text { Encapsulated BP })_{\mathrm{IC}_{50}}}
$$

\section{The drug-protective effects of LPPC}

To evaluate the drug-protective effects of LPPC, changes in the cytotoxic activity of BP and BP/LPPC were measured. First, both nonencapsulated BP and BP/LPPC were incubated in $\mathrm{H}_{2} \mathrm{O}$ and in protein-rich solutions $(10 \% \mathrm{FBS}$ in PBS) with different $\mathrm{pH}$ values at $4^{\circ} \mathrm{C}$ and $37^{\circ} \mathrm{C}$. In addition, nonencapsulated BP and BP/LPPC were exposed to oxygen for 24 hours. Finally, DBTRG-05MG and RG2 cells were treated with pretreated $\mathrm{BP}$ and $\mathrm{BP} / \mathrm{LPPC}$. Changes in the $\mathrm{IC}_{50}$ values of BP and BP/LPPC were determined by an MTT colorimetric assay.

\section{The delivery-enhancing effects of LPPC in vitro}

DBTRG-05MG cells were seeded in six-well tissue culture plates on glass coverslips at a density of $2 \times 10^{5}$ cells per well. Subsequently, the cells were treated with PBS and $50 \mathrm{mg} / \mathrm{mL}$ of $\mathrm{BP}$ or $\mathrm{BP} / \mathrm{LPPC}$ (containing $50 \mathrm{mg} / \mathrm{mL}$ of BP). After incubation at $37^{\circ} \mathrm{C}$ for 0 minutes, 15 minutes, 30 minutes, 60 minutes, and 120 minutes, the media was removed from the cells, and the cells were then washed with PBS, fixed with $4 \%(w / w)$ paraformaldehyde in PBS, and imaged at $400 \times$ magnification using a Zeiss LSM 510 META confocal microscope (Carl Zeiss Meditec AG, Jena, Germany). Incubation under each condition was performed in triplicate.

To measure the accumulation of BP, $2.5 \times 10^{5}$ cells/well were treated with $50 \mathrm{mg} / \mathrm{mL}$ of BP or BP/LPPC. After incubation at $37^{\circ} \mathrm{C}$ for 0 minutes, 15 minutes, 30 minutes, 45 minutes, and 60 minutes, the cells were lysed, and BP was extracted by phenol/chloroform and measured by a fluorescence spectrophotometer (Hitachi Ltd.).

For analysis of the colocalization of BP/LPPC, LPPC was first labeled with DiO fluorescent dye and was then used to encapsulate BP. Subsequently, the cells that were seeded on glass coverslips were treated with BP/DiO-LPPC (containing $50 \mathrm{mg} / \mathrm{mL}$ of BP). After incubation at $37^{\circ} \mathrm{C}$ for 0 minutes, 15 minutes, 60 minutes, and 120 minutes, the media was removed from the cells, and the cells were then washed with PBS, fixed with 4\% (w/w) paraformaldehyde in PBS, and then incubated with LysoTracker Red DND-99 lysosomal staining probe (Thermo Fisher Scientific). The colocalization of BP and LPPC was imaged at 400× magnification using a Zeiss LSM 510 META confocal microscope (Carl Zeiss).

\section{Antitumor activity of BP/LPPC}

Female athymic mice (4-6 weeks of age) were obtained from the National Laboratory Animal Center (Taipei, Taiwan). All procedures were conducted in compliance with the standard operating procedures of the Laboratory Animal Center of Chung Shan Medical University (Taichung, Taiwan). Nude mice $(n=10)$ were implanted via subcutaneous $(\mathrm{sc})$ injection with $5 \times 10^{6}$ DBTRG-05MG cells. The tumor-bearing animals were treated with BP (100 mg BP/kg), BP/LPPC, or vehicle by IV injection every 2 days after tumor establishment ( $\sim 50 \mathrm{~mm}^{3}$ tumor volume). In another set of experiments, the tumor-bearing animals were treated with $\mathrm{BP}(100 \mathrm{mg} \mathrm{BP} / \mathrm{kg})$, 
BP/LPPC, or vehicle by intratumoral injection every 2 days after tumor implantation for 3 days. Tumor size was measured with a caliper, and tumor volume was calculated as $\mathrm{L} \times \mathrm{H} \times \mathrm{W} \times 0.5236$. The animals were sacrificed when the tumor volume exceeded $2,000 \mathrm{~mm}^{3}$. Tumor and normal tissue sections were observed and photographed under a light microscope at a magnification of $400 \times$.

\section{Immunohistochemical staining}

Paraffin-embedded sections were obtained from the tumors treated with BP/LPPC by IV or intratumoral injection and were processed for immunohistochemical staining. Briefly, the slides were treated with $3 \%$ hydrogen peroxide in $1 \times$ PBS for 10 minutes to block endogenous peroxidase activity after being dewaxed and rehydrated. Next, the sections were washed three times with $1 \times$ TBS containing $0.05 \%$ Tween 20 for 5 minutes each time, and nonspecific antibody binding was blocked by $10 \%$ FBS in PBS for 10 minutes at room temperature. The sections were incubated with a rabbit polyclonal anticleaved caspase-3 (Asp175) antibody (1/1,000 dilution; Cell Signaling Technology) at $4^{\circ} \mathrm{C}$ overnight, and the immune complexes were visualized using a horseradish peroxidase-conjugated antigoat IgG secondary antibody (1/1,000 dilution; Santa Cruz Biotechnology inc., Dallas, TX, USA). An LSAB2 system (DAKO, Carpinteria, CA, USA) was used to visualize the immune complexes by incubating the sections with $0.5 \mathrm{mg} / \mathrm{mL}$ diaminobenzidine and $0.03 \%(\mathrm{v} / \mathrm{v}) \mathrm{H}_{2} \mathrm{O}_{2}$ in PBS for 10 minutes. Finally, the sections were counterstained with hematoxylin, mounted, observed under a light microscope at $400 \times$ magnification, and photographed.

\section{Statistical analysis}

The results were analyzed using the SAS statistical software package (SAS Institute Inc., Cary, NC, USA). The results are expressed as the mean \pm standard deviation. An analysis of variance test was used when comparing multiple samples. Differences with $P<0.05$ were considered statistically significant.

\section{Results}

\section{The characteristics of BP/LPPC}

The particle sizes of different BP/LPPC mixtures (volume ratios of BP/LPPC from 0.5:10 to 3:10) ranged from $200 \mathrm{~nm}$ to $280 \mathrm{~nm}$ (Figure 1A). The average zeta-potential of these different BP/LPPC mixtures was $\sim 38 \mathrm{mV}$ (Figure 1B). For BP encapsulation, the maximal encapsulation capacity of $1 \mathrm{mg}$ of LPPC was $\sim 830 \mu \mathrm{g}$ of BP at 3:10 and 4:10 (v/v) ratios of BP/LPPC (Figure 1C). According to the results of particle size, zeta-potential, and BP encapsulation capacity assessments, a 3:10 ratio of BP/LPPC was chosen for the following experiments.

The in vitro drug release of BP from BP/LPPC in $\mathrm{H}_{2} \mathrm{O}$ was measured, and the kinetics of drug release showed that only $6 \%-13 \%$ of the encapsulated BP was released from BP/LPPC after incubation at $4{ }^{\circ} \mathrm{C}$ (Figure 1D). Approximately $25 \%$ of the encapsulated BP had been released into the media after 12 days at $37^{\circ} \mathrm{C}$. However, when BP/LPPC was incubated in protein-rich solution at $37^{\circ} \mathrm{C}$, over $70 \%$ of the encapsulated $\mathrm{BP}$ was released into the media after 4 days (Figure 1E).

\section{The cytotoxic activity of BP/LPPC against tumor cells}

To further determine whether the encapsulation of BP into BP/LPPC could enhance its cytotoxicity, different GBM cell lines were analyzed for cell viability after BP or BP/LPPC treatment. The results indicated that the $\mathrm{IC}_{50}$ levels for nonencapsulated BP ranged from $54.9 \mu \mathrm{g} / \mathrm{mL}$ (DBTRG-05MG cells) to $122.7 \mu \mathrm{g} / \mathrm{mL}$ (GBM8901 cells); however, treating the cells with BP/LPPC resulted in lower $\mathrm{IC}_{50}$ values in all six of the cancer cell lines that were tested. Compared with nonencapsulated $\mathrm{BP}$, the $\mathrm{IC}_{50}$ levels of BP/LPPC were markedly decreased in all cancer cell lines, ranging from $11.6 \mu \mathrm{g} / \mathrm{mL}$ to $17.5 \mu \mathrm{g} / \mathrm{mL}$ (Table 1). Thus, BP/LPPC was able to enhance the cytotoxic activity of BP by between 4.5 - and 8.5 -fold. These results were dramatic when compared with other delivery methods, such as BP/liposomes (Table 1). In addition, the $\mathrm{IC}_{50}$ levels of BP/LPPC ranged from $24.3 \mu \mathrm{g} / \mathrm{mL}$ to $32.2 \mu \mathrm{g} / \mathrm{mL}$ for normal cells, such as SVEC4-10 and MDCK cells (Table 1). In this study, empty LPPC did not have cytotoxic effects on any cancer cell lines when applied at a dosage equivalent to the $\mathrm{IC}_{50}$ of $\mathrm{BP} / \mathrm{LPPC}$.

\section{LPPC protected BP against instability induced by proteins, $\mathrm{pH}$ and, oxygen}

To verify the stability of BP in BP/LPPC for cancer therapy, nonencapsulated $\mathrm{BP}$ and $\mathrm{BP} / \mathrm{LPPC}$ were preincubated either in $\mathrm{H}_{2} \mathrm{O}$ at $4^{\circ} \mathrm{C}$ (storage condition) or in a $10 \%$ FBS solution at $37^{\circ} \mathrm{C}$ (bioactive condition), and changes in the $\mathrm{IC}_{50}$ values of $\mathrm{BP}$ and $\mathrm{BP} / \mathrm{LPPC}$ were measured. The results, shown in Figure 2A, indicated that the $\mathrm{IC}_{50}$ values of freshly prepared BP and BP/LPPC in both cell lines were $55 \mu \mathrm{g} / \mathrm{mL}$ and $12 \mu \mathrm{g} / \mathrm{mL}$, respectively. For BP preincubated in $\mathrm{H}_{2} \mathrm{O}$ at $4^{\circ} \mathrm{C}$ for 4 hours, the $\mathrm{IC}_{50}$ values dramatically increased (Figure 2B). A similar increase in $\mathrm{IC}_{50}$ was also observed for $\mathrm{BP}$ preincubated in $10 \% \mathrm{FBS}$ solution at $37^{\circ} \mathrm{C}$ (Figure 2C). 
A
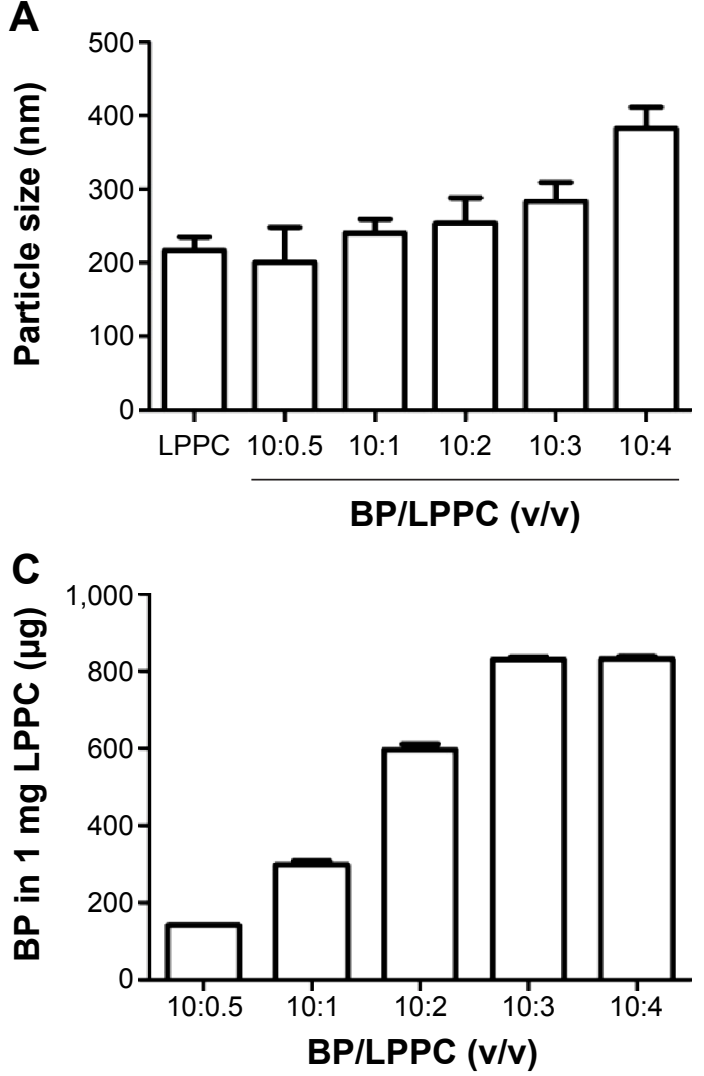

B

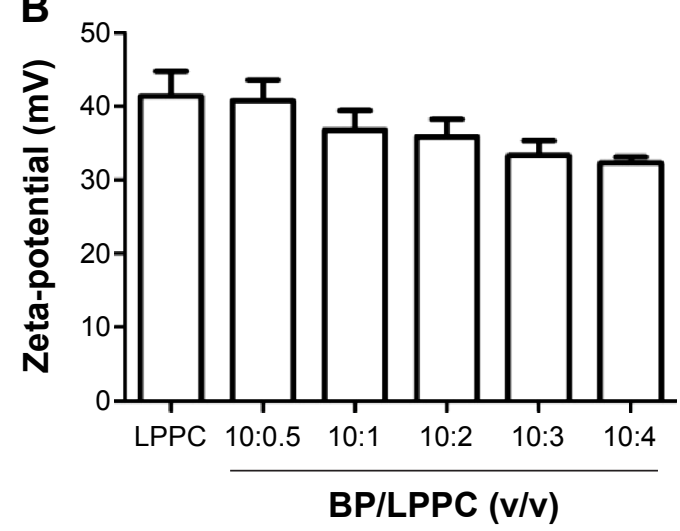

D

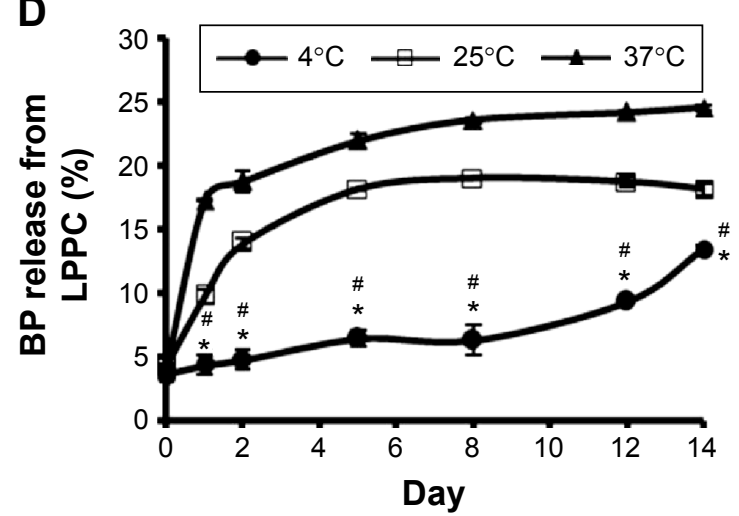

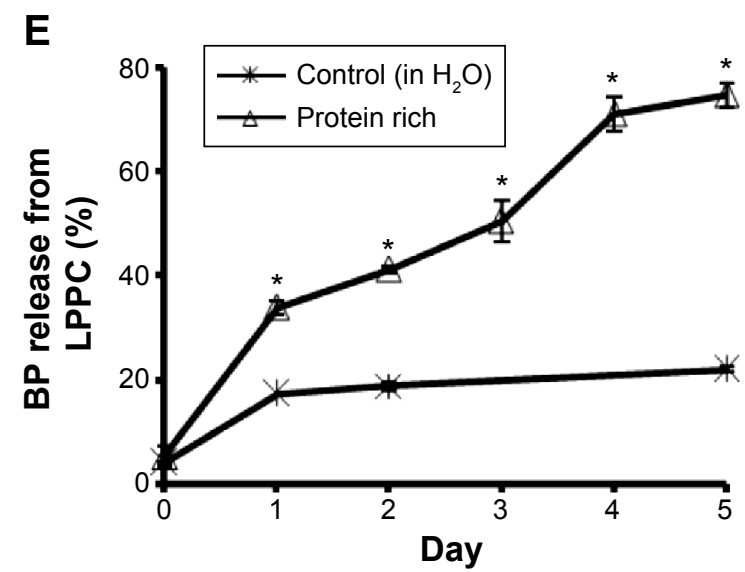

Figure I BP/LPPC characteristics.

Notes: BP solution (I M) encapsulated in LPPC at various volume ratios. The (A) particle size, (B) zeta-potential, and (C) BP encapsulation of BP/LPPC were measured. (D) BP release from BP/LPPC in $\mathrm{H}_{2} \mathrm{O}$ at $4^{\circ} \mathrm{C}, 25^{\circ} \mathrm{C}$, and $37^{\circ} \mathrm{C}$. $* P<0.05$, compared with the $25^{\circ} \mathrm{C}$ group; ${ }^{*} \mathrm{P}<0.05$, compared with the $37^{\circ} \mathrm{C}$ group. (E) BP release from $\mathrm{BP} / \mathrm{LPPC}$ in protein-rich solution (containing $10 \% \mathrm{FBS}$ ) at $37^{\circ} \mathrm{C}$. After the incubation, the percentage of BP in each supernatant was measured and compared with the total amount of $B P(n=6) . * P<0.05$, compared with the control group.

Abbreviations: BP, $n$-butylidenephthalide; FBS, fetal bovine serum; LPPC, lipo-PEG-PEI complex.

However, regardless of preincubation conditions, the $\mathrm{IC}_{50}$ value of BP/LPPC was similar to that of a freshly prepared BP/LPPC (Figure 2B and C).

To determine whether LPPC protects BP from damage in acidic or alkaline solution, the $\mathrm{IC}_{50}$ values of $\mathrm{BP}$ and $\mathrm{BP} / \mathrm{LPPC}$ in both solutions following preincubation in buffers of different $\mathrm{pH}$ values were measured. When BP was preincubated in solutions at $\mathrm{pH} 6$ and 8, its $\mathrm{IC}_{50}$ in DBTRG-05MG cells significantly increased (Figure 2D and E). However, following incubation in buffers with these same $\mathrm{pH}$ values, BP encapsulated in LPPC retained the same $\mathrm{IC}_{50}$ values at $\mathrm{pH} 7$ and 7.5 (Figure 2D and $\mathrm{E}$ ). When $\mathrm{BP}$ was exposed to oxygenated buffers, its $\mathrm{IC}_{50}$ was increased to $700 \mathrm{mg} / \mathrm{mL}$. However, LPPC can protect BP against oxidation and maintain the 
Table I The cytotoxicity of BP/LPPC $\left(\mathrm{IC}_{50}\right)$ in different brain tumor and normal cells

\begin{tabular}{|c|c|c|c|c|c|}
\hline Cell line & Tumor type & $\mathbf{B P a}$ & BP/LPPC ${ }^{b}$ & BP/Lipo & Fold $^{a / b}$ \\
\hline \multicolumn{6}{|l|}{ Brain tumor cells } \\
\hline DBTRG-05MG & Human GBM & $54.9 \pm 2.8^{c}$ & $11.6 \pm 3.4^{\mathrm{d}}$ & $71.4 \pm 6.0^{\circ}$ & 4.72 \\
\hline G5T/VGH & Human GBM & $55.8 \pm 1.9^{c}$ & $12.1 \pm 1.9^{d}$ & $94.7 \pm 3.2^{\mathrm{e}}$ & 4.62 \\
\hline GBM840I & Human GBM & $108.5 \pm 0.8^{c}$ & $17.5 \pm 1.5^{d}$ & $145.7 \pm 1.3^{\mathrm{e}}$ & 6.22 \\
\hline GBM890I & Human GBM & $122.7 \pm 2.3^{c}$ & $14.4 \pm 0.3^{d}$ & $151.2 \pm 0.5^{e}$ & 8.54 \\
\hline RG2 & Rat GBM & $57.6 \pm 2.6^{c}$ & $11.9 \pm 0.1^{\mathrm{d}}$ & $72.1 \pm 2.3^{e}$ & 4.84 \\
\hline NI8 & Mouse neuroblastoma & $58.3 \pm 1.4^{c}$ & $13.1 \pm 1.5^{d}$ & $118.7 \pm 3.2^{\mathrm{e}}$ & 4.46 \\
\hline \multicolumn{6}{|l|}{ Normal cells } \\
\hline SVEC & Mouse endothelial cell & $106.9 \pm 1.0^{c}$ & $24.3 \pm 2.1^{d}$ & $110.5 \pm 2.9^{c}$ & 4.40 \\
\hline MDCK & Dog normal kidney & $131.5 \pm 3.6^{c}$ & $32.2 \pm 1.6^{d}$ & $169.0 \pm 3.0^{c}$ & 4.08 \\
\hline
\end{tabular}

Notes: All values are mean \pm standard deviation $(n=3$, units of BP concentration: $\mu \mathrm{g} / \mathrm{mL}$ ). Values in the same row with different superscript letters are significantly different at $P<0.05$. ${ }^{a / b}\left(I C_{50}\right.$ of $\left.B P\right) /\left(I C_{50}\right.$ of BP/LPPC). ${ }^{c-e} V$ alues in the same row with different superscript letters are significantly different at $P<0.05$.

Abbreviations: BP, $n$-butylidenephthalide; GBM, glioblastoma multiforme; LPPC, lipo-PEG-PEI complex; IC $_{50}$, half maximal inhibitory concentration.

cytotoxicity of BP for up to 9 months, which may be useful for cancer therapy (Figure $2 \mathrm{~F}-\mathrm{H}$ ).

\section{The delivery efficiency of BP/LPPC}

To observe changes in delivery efficiency, the cellular accumulation of nonencapsulated BP and BP/LPPC was determined by confocal microscopy. DBTRG-05MG cells were treated with equal concentrations of nonencapsulated BP and BP/LPPC, and the accumulation of BP in the cytosol was measured over time. The results showed that cytosolic drug was undetectable in the cells that were incubated with nonencapsulated BP for 30 minutes (Figure 3A). However, $\mathrm{BP} / \mathrm{LPPC}$ could rapidly accumulate in the cytosol during a 15-minute incubation (Figure 3B). Furthermore, after determining the amount of $\mathrm{BP}$ in the cells, BP/LPPC treatment caused the accumulation of $13 \mu \mathrm{g}$ more BP in cells within 15 minutes than in cells treated with nonencapsulated $\mathrm{BP}$ alone, and BP/LPPC treatment continued to gradually increase cellular BP levels over longer times (Figure 3C). In addition, Figure 3D demonstrates that LPPC transported BP to lysosomes via endocytosis. Substantial transport of BP/ LPPC to cytoplasm and lysosomes was observed after only a 15-minute incubation. Subsequently, BP drug was released abundantly in the cytoplasm after a 60-minute incubation. These results provided evidence of the rapid internalization of LPPC and the release of drug from LPPCs within lysosomes at later time points. From these results, one can infer that LPPC enhances the delivery of BP into cells, thereby increasing the cytotoxic efficacy of the drug.

\section{In vivo suppression of tumor growth by BP/LPPC}

Mice bearing DBTRG-05MG tumors were treated with BP $(100 \mathrm{mg} / \mathrm{kg}$ ), empty LPPC, or BP/LPPC (containing
$100 \mathrm{mg} / \mathrm{kg} \mathrm{BP}$ ) once every 2 days by IV injection. After 14 days, the animals treated with BP/LPPC showed a significant suppression of DBTRG-05MG tumor growth compared with the untreated controls, the nonencapsulated BP-treated animals, and the empty LPPC-treated animals (Figure 4A). This result was validated using a different treatment: intratumoral injection of BP. After 14 days of treatment, significant suppression of tumor cell growth by BP/LPPC was again observed (Figure 4B). In these experiments, both treatments with BP/LPPC (IV and intratumoral injection) inhibited DBTRG-05MG tumor growth by $\sim 85 \%-88 \%$. These results show that BP/LPPC was more effective than nonencapsulated $\mathrm{BP}$ in inhibiting GBM tumor growth. Additionally, histological analysis showed that GBM tissues treated with BP/LPPC in vivo displayed increased caspase-3 activity and tumor cell apoptosis (Figure 4C).

\section{Discussion}

In this study, we first used a liposome-based nanoparticle complex (LPPC) to encapsulate BP to overcome its problems of unstable structure and water insolubility. The dimerization of BP under natural conditions through cycloaddition leads to oxidation or ring cleavage of the BP monomer and interferes with BP's antitumor activity. ${ }^{17}$ In oxygenic solution, BP changes its formation and loses its function. ${ }^{18}$ Additionally, after BP was incubated in a $10 \%$ FBS solution, which disrupted its antitumor function via the presence of serum proteins, the cytotoxicity of BP was dramatically decreased (Figure 2). Serum proteins might interact with BP and destroy its structure. These results - that BP loses its cytotoxic activity in the presence of serum - might be similar to camptothecin. Serum proteins such as albumin bind to camptothecin and interact with its lactone, carboxylate, and self-aggregated forms, leading to lower cytotoxic 
A

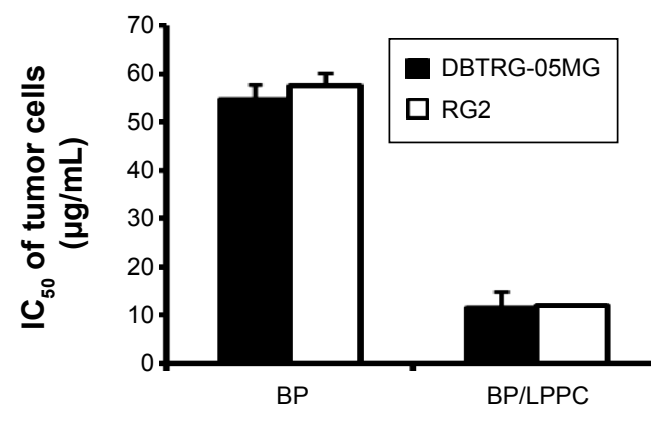

C

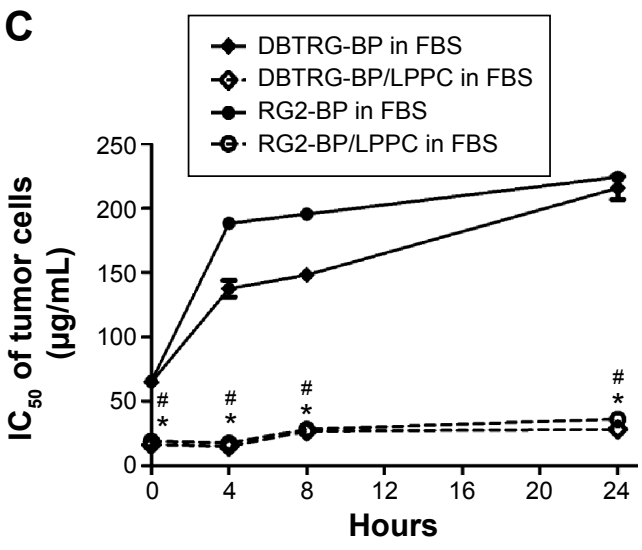

E

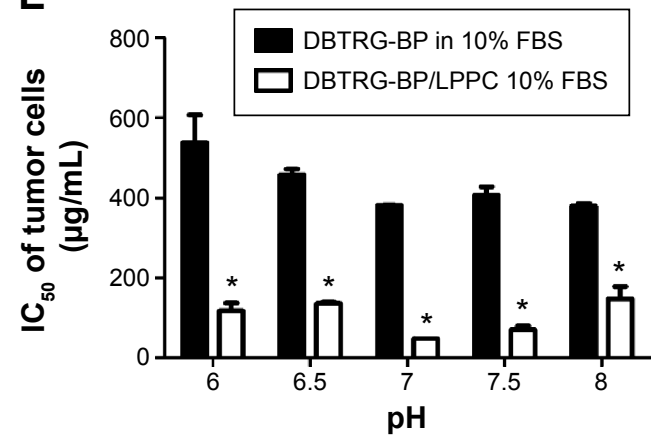

G

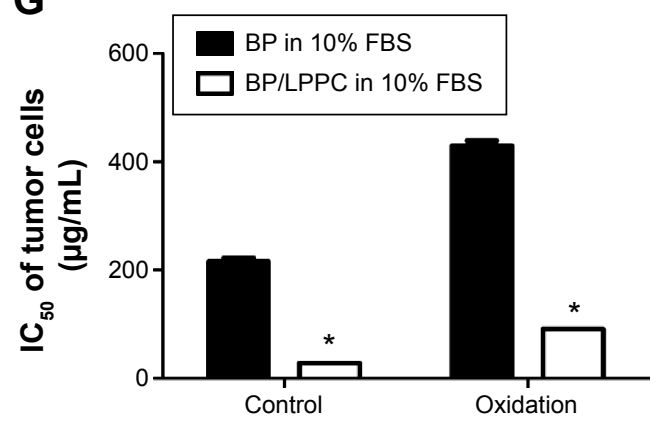

B

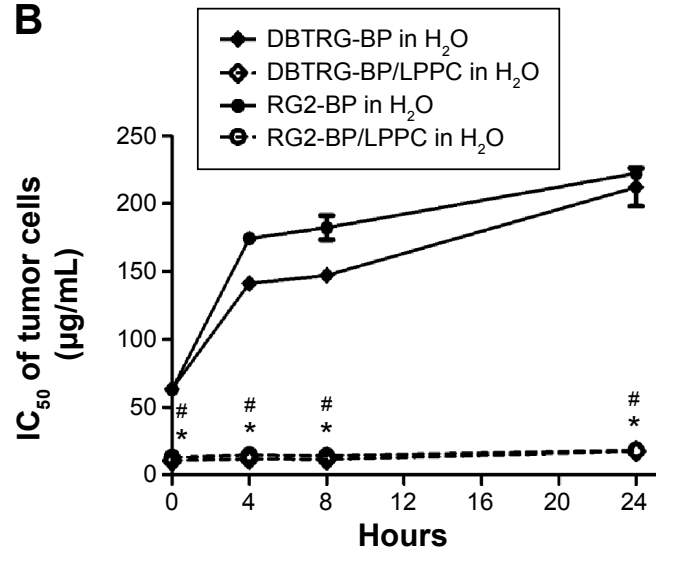

D

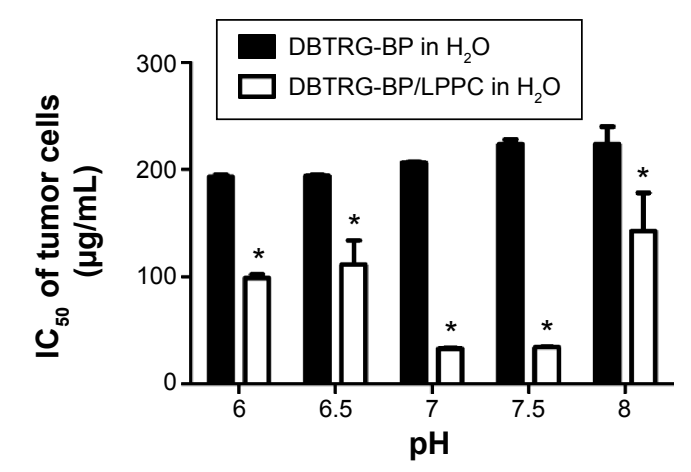

$\mathbf{F}$
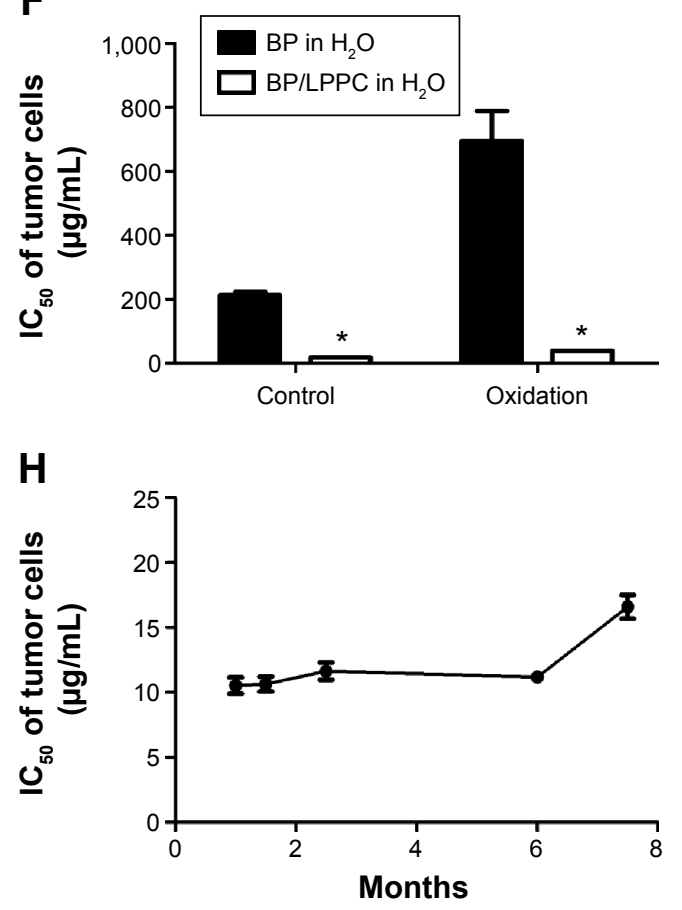

Figure 2 LPPC protected BP against the loss of its antitumor activity in protein-rich, oxygenic, and acid/alkaline solutions.

Notes: (A) IC $\mathrm{C}_{50}$ of BP and BP/LPPC in DBTRG-05MG and RG2 cells. BP and BP/LPPC were preincubated in (B) $\mathrm{H}_{2} \mathrm{O}$ or (C) $10 \%$ FBS solution at $37^{\circ} \mathrm{C}$, after which both GBM cell lines were treated with the preincubated BP or BP/LPPC. As the preincubation time increased, the IC $\mathrm{C}_{50}$ values for $\mathrm{BP}$ and $\mathrm{BP} / \mathrm{LPPC}$ were determined. $* P<0.05$, compared with DBTRG-BP in $\mathrm{H}_{2} \mathrm{O} ;{ }^{\# P}<0.05$, compared with RG2-BP in $\mathrm{H}_{2} \mathrm{O}$. BP and BP/LPPC were also preincubated in (D) $\mathrm{H}_{2} \mathrm{O}$ or (E) I0\% FBS solutions ranging from pH 6 to 8 at $37^{\circ} \mathrm{C}$, after which both GBM cell lines were treated with the preincubated BP or BP/LPPC. The IC ${ }_{50}$ values of BP and BP/LPPC were measured by MTT. BP and BP/LPPC were preincubated in $(\mathbf{F}) \mathrm{H}_{2} \mathrm{O}$ with oxygen or $(\mathbf{G}) 10 \% \mathrm{FBS}$ solution with oxygen for 24 hours, and their $\mathrm{IC}_{50}$ values in DBTRG-05MG cells were determined. $* P<0.05$, compared with nonencapsulated BP. (H) The cytotoxic activity of BP/LPPC in storage.

Abbreviations: BP, $n$-butylidenephthalide; FBS, fetal bovine serum; GBM, glioblastoma multiforme; IC 5 , $50 \%$ inhibitory concentration; LPPC, lipo-PEG-PEI complex. 

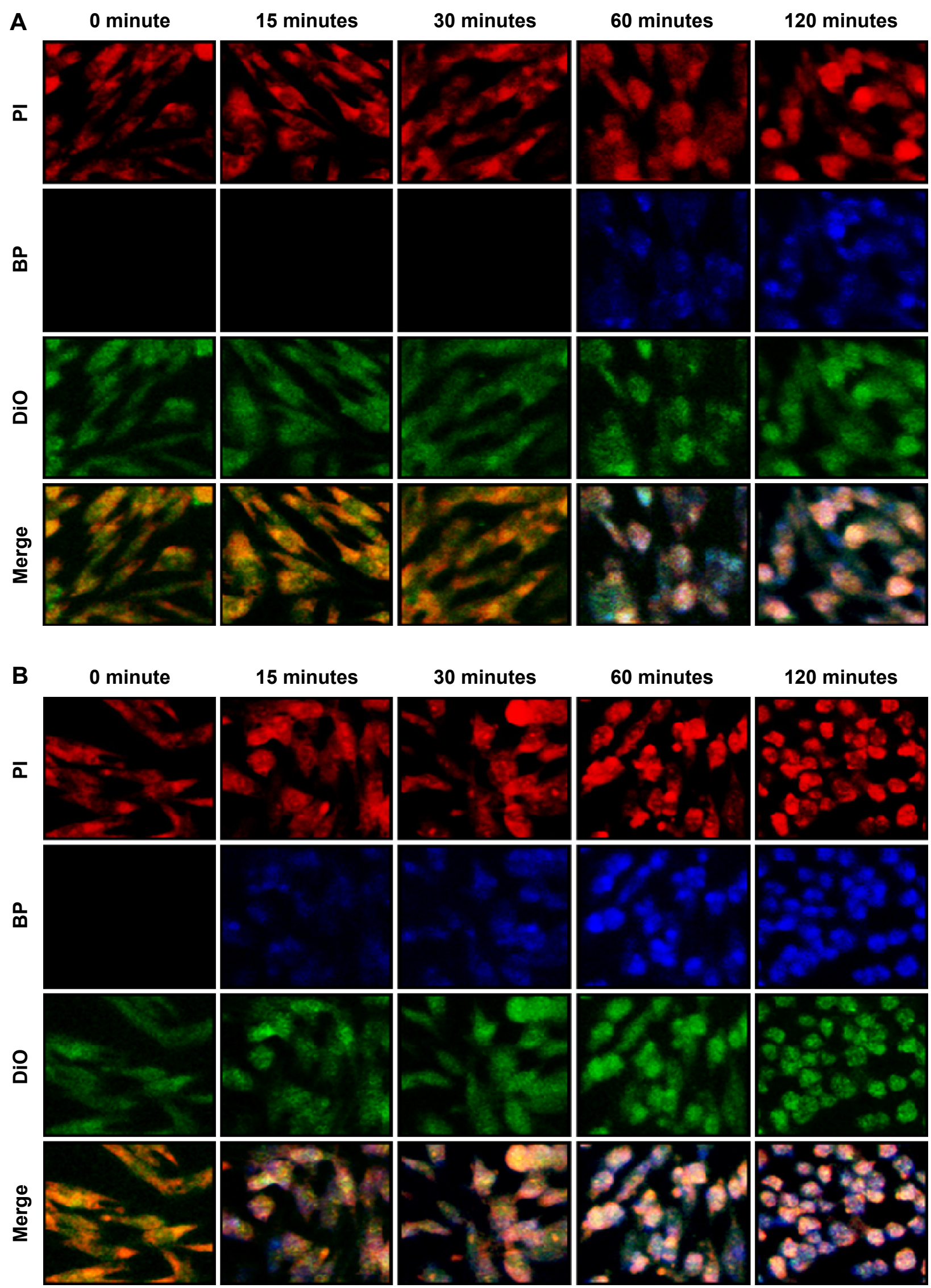

Figure 3 (Continued) 


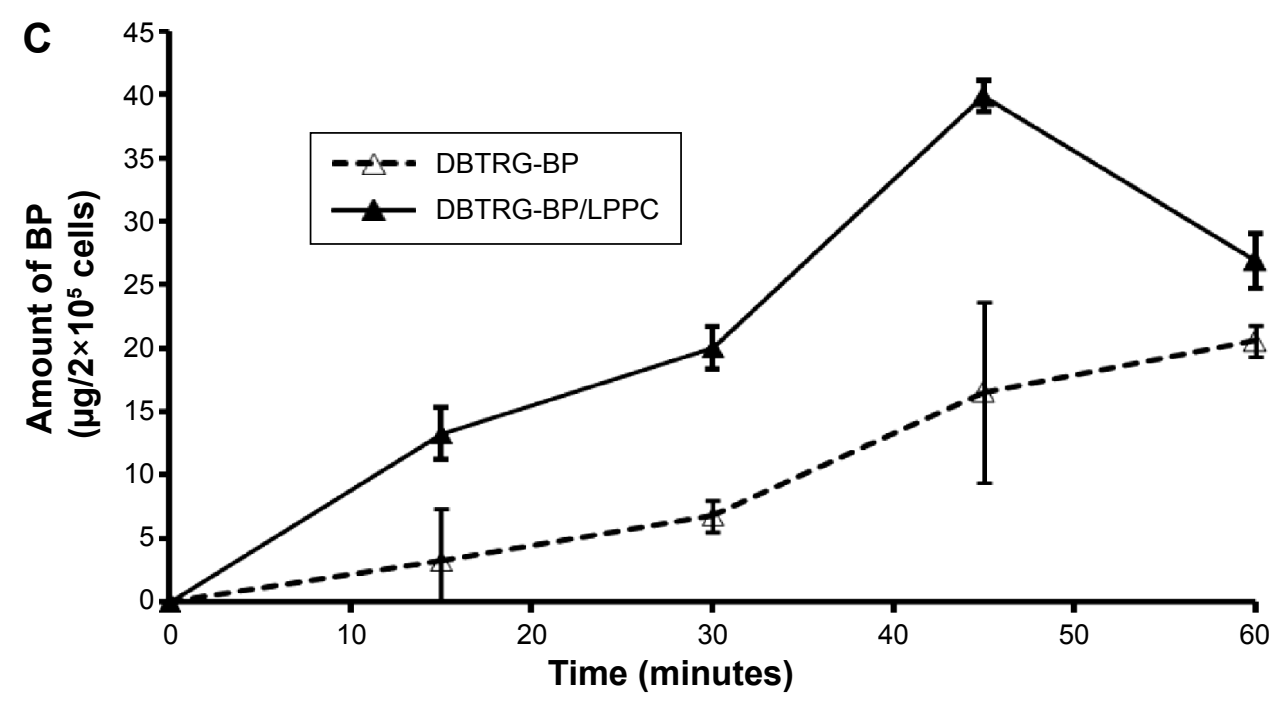

D 0 minute 15 minutes 60 minutes
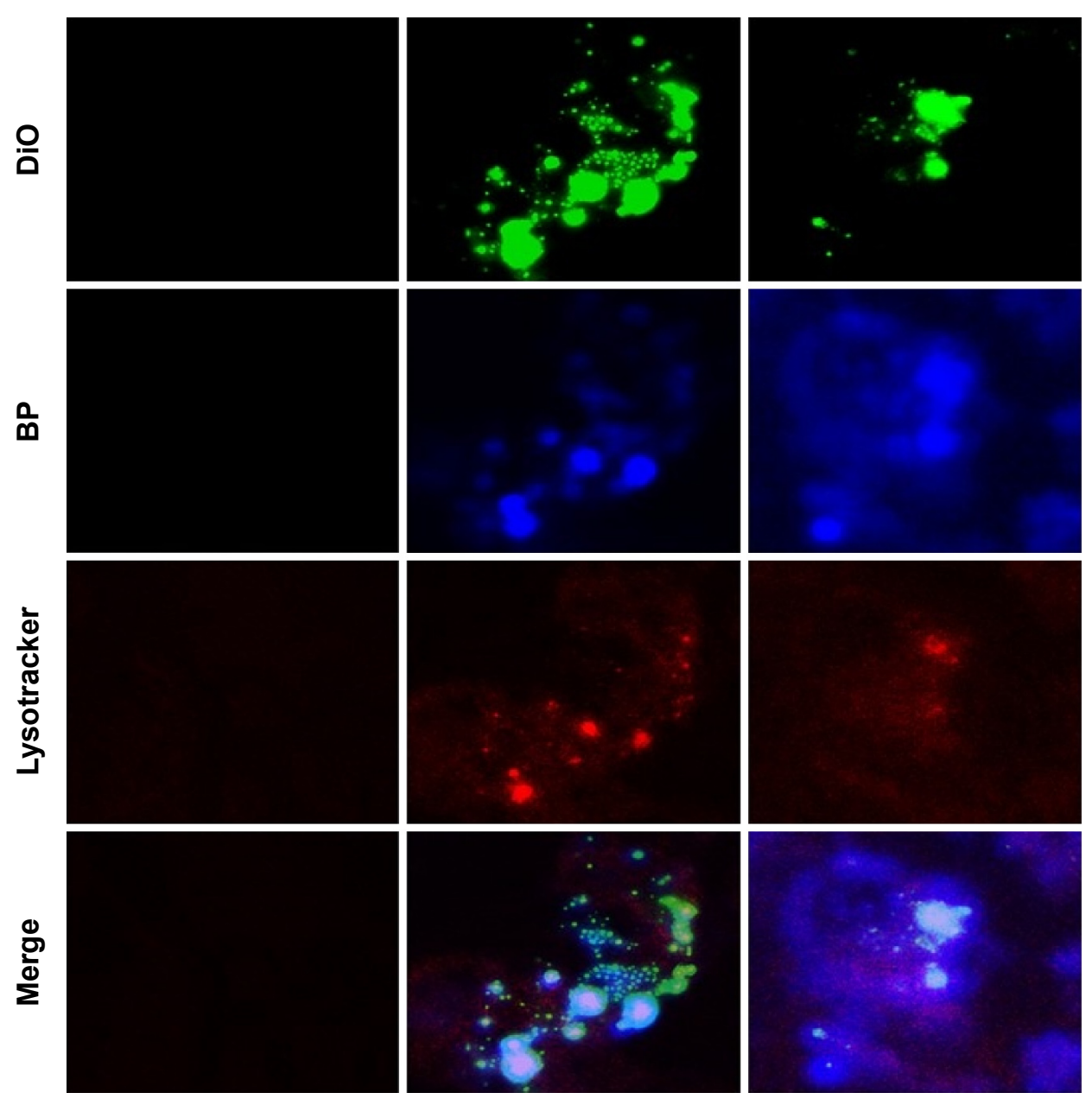

Figure 3 The uptake of BP/LPPC complex in DBTRG-05MG cells.

Notes: (A) BP or (B) BP/LPPC (50 $\mu \mathrm{g} / \mathrm{mL})$ was added to DBTRG-05MG cells and incubated for 15 minutes, 30 minutes, 60 minutes, and I20 minutes. Cell fluorescence was analyzed by confocal microscopy at 400X. PI red fluorescence: nuclei; blue fluorescence: BP drug; DiO green fluorescence: cell membrane. (C) The amount of BP in the cells. After treatment with BP, the cells were harvested and lysed. BP was extracted and measured by a fluorescence spectrophotometer. (D) Colocalization of BP/LPPC. BP/LPPC was added to DBTRG-05MG cells and incubated for 15 minutes and 60 minutes. Cell fluorescence was analyzed by confocal microscopy at 400x. DiO green fluorescence: DiO-labeled LPPC; blue fluorescence: BP drug; LysoTracker red fluorescence: lysosome.

Abbreviations: BP, $n$-butylidenephthalide; LPPC, lipo-PEG-PEI complex; PI, propidium iodide. 
A

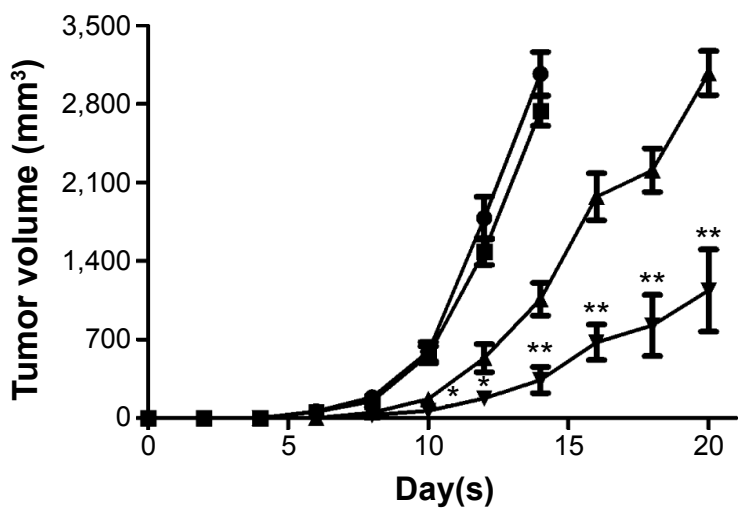

B

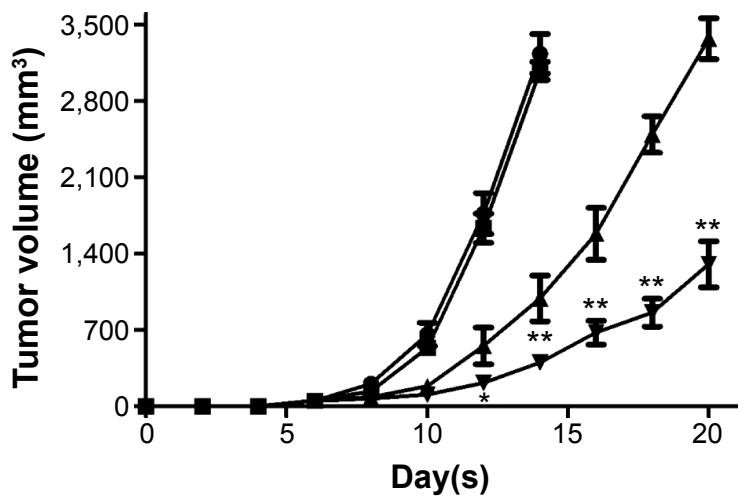

$-\mathrm{PBS} \leftarrow$ LPPC $\rightarrow \mathrm{BP} \rightarrow \mathrm{BP} / \mathrm{LPPC}$

C
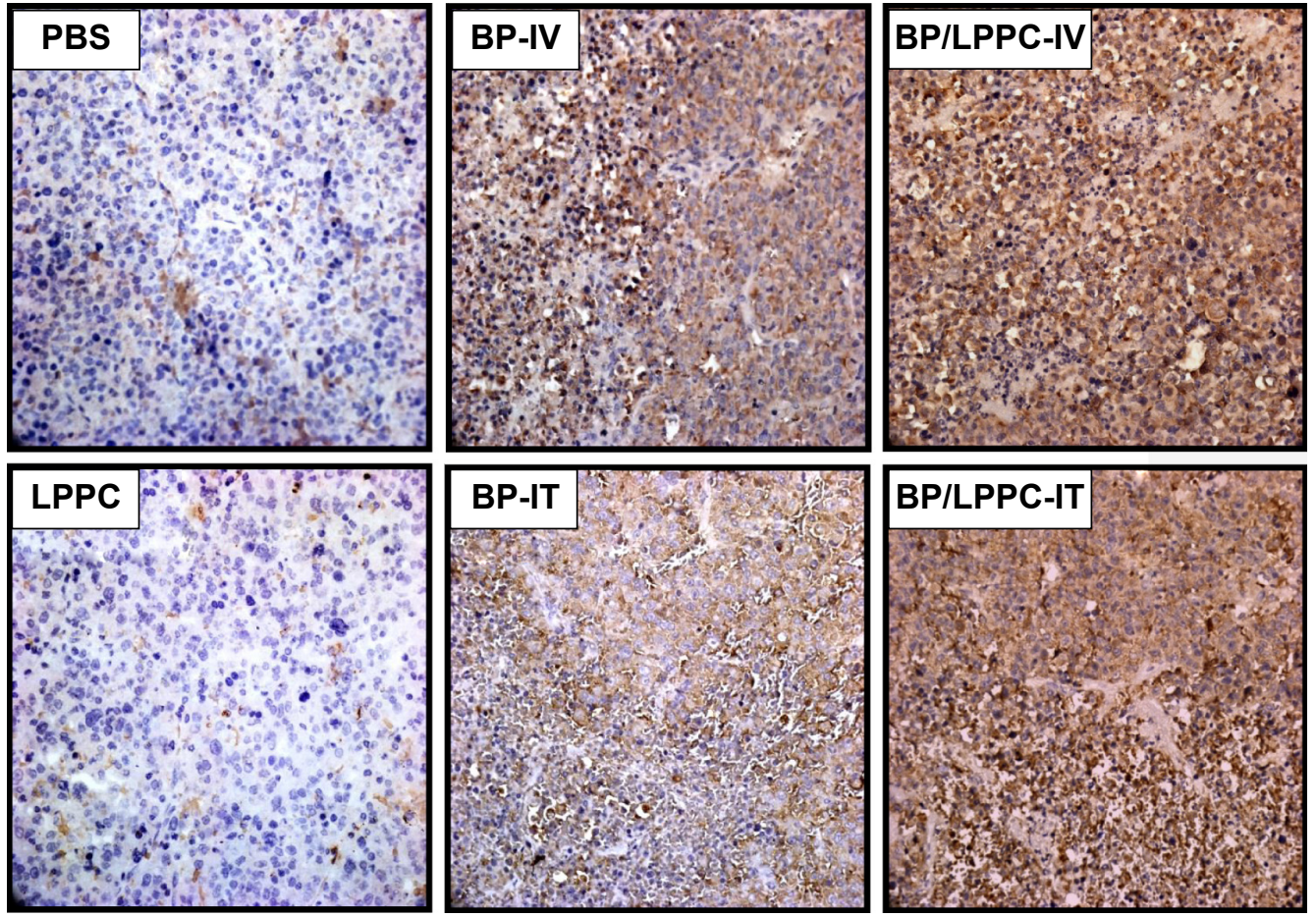

Figure 4 The effects of BP/LPPC on tumor growth in vivo.

Notes: (A) Nude mice bearing DBTRG-05MG tumors ( $\mathrm{n}=10$ per group) were treated with BP, LPPC, or BP/LPPC (I00 mg/kg BP) by intravenous injection once every 2 days after their tumor masses reached $50 \mathrm{~mm}^{3}$. (B) Tumor-bearing animals were treated with BP (100 mg BP/kg), BP/LPPC, or vehicle by intratumoral injection every 2 days after tumor implantation for 3 days ( $n=10$ per group). Tumor volume was measured every 2 days after treatment. Significant differences after treatment were found for the BP/LPPC group compared with the BP-treated group $(* P<0.05$, $* * P<0.01)$. (C) Cleaved caspase-3 expression in DBTRG-05MG tumors after BP/LPPC treatment. The sections of tumor masses were measured by immunohistochemistry staining of cleaved caspase- 3 .

Abbreviations: BP, $n$-butylidenephthalide; PBS, phosphate-buffered saline; LPPC, lipo-PEG-PEl complex.

activity. ${ }^{19-21}$ Various nanoparticles have been developed to encapsulate camptothecin to decrease its interaction with serum albumin, which enhances the stability of the drug. ${ }^{22-24}$ In our results, LPPC-encapsulated BP retained its cytotoxic activity even when incubated in a protein-rich, oxygenic, or acid/alkaline solution (Figure 2). Collectively, the results showed that LPPC encapsulation protects BP against serum protein interactions, conformational changes, and oxidation.
Therefore, LPPC encapsulation dramatically raised the cytotoxic activity of BP and enhanced its stability in the presence of serum.

LPPC provides an advanced encapsulation method that was able to efficiently deliver BP into tumor cells. When compared with nonencapsulated BP, BP/LPPC not only dramatically increased the cytotoxic activity of BP from 4.5- to 8.5-fold in all tested GBM tumor cells in vitro (Table 1) but 
also inhibited $85 \%$ of subcutaneous tumor growth in vivo (Figure 4). In our previous report, it was found that LPPC encapsulation could also suppress the proliferation of drugresistant cells and elevate the antiproliferative effect of a drug. ${ }^{14}$ The increased antiproliferative effect of BP/LPPC may be due to its increased ability to rapidly penetrate and accumulate in cells (Figure 3). This high level of efficient transport into cells is supported by the fact that LPPC is a good shuttle for drugs across the cell membrane. LPPC has been shown to be an excellent drug transporter, capable of delivering large quantities of encapsulated molecules across the cell membrane quickly, which would likely explain the benefits observed by BP/PC treatment in GBM cells.

LPPC-encapsulated BP significantly increased the inhibition of subcutaneous tumor growth when administered by an IV route. The mechanism of tumor growth inhibition by IV injection of BP/LPPC may involve the tumor vasculature. It has been proposed that the leakiness of tumor blood vessels may increase the access of therapeutic vehicles to a tumor mass. Usually, tumor blood vessels are structurally abnormal and have endothelial gaps that range in size from $200 \mathrm{~nm}$ to $2 \mu \mathrm{m} .{ }^{25}$ In addition, cationic liposomes, which are promising carriers for tumorigenic targeting, have been found to selectively target angiogenic endothelial cells in tumors. ${ }^{26}$ Thus, BP/LPPC, a cationic polymer liposome of $200-280 \mathrm{~nm}$, should be able to accumulate near tumor cells due to the leakiness of tumor vasculature and therefore selectively deliver BP to a tumor area. This efficient delivery is likely to result in highly selective cytotoxicity against the tumor via its angiogenic endothelial cells. In addition, drug-loaded LPPC should be able to release a drug in a tumor area in a stable and controlled manner. ${ }^{14}$ LPPC, which permits efficient transmembrane transportation (Figure 3), should lead to highly efficient penetration of a drug into tumor cells.

In addition, this study demonstrated that the administration of $\mathrm{BP} / \mathrm{LPPC}$ via intratumoral injection also provided significant tumor growth inhibition. In clinical practice, local administration, such as intratumoral or intracranial injection, is a therapeutic method for treating brain tumors. ${ }^{27-29}$ This therapy is an alternative to vascular administration, as it bypasses the blood-brain barrier and delivers therapeutic agents directly into the brain. ${ }^{30}$ Therefore, athymic mice were implanted with GBM tumors subcutaneous and were treated with BP/LPPC by intratumoral injection. These results demonstrated that BP accumulated in tumor areas and maximally enhanced the antitumor effects of cytotoxic chemotherapy. In this study, the improved therapeutic effect of LPPC-encapsulated BP on GBM tumors further demonstrated that LPPC is a good drug carrier for drug transport.

\section{Conclusion}

In brief, this study showed that LPPC encapsulation improves the cytotoxicity of BP against cancer cells through rapid internalization. Our findings show that LPPC is a good vector for the encapsulation of hydrophobic antitumor drugs such as BP, as it appears to increase the cytotoxicity of BP in vivo. Future studies are underway to determine the potential of LPPC encapsulation as a means to enhance selective delivery of BP in vivo using antitumor antibodies on the LPPC surface.

\section{Acknowledgments}

This work was partially supported by UST-UCSD International Center of Excellence in Advanced Bioengineering sponsored by the Ministry of Science and Technology I-RiCE Program under grant number MOST 103-2911I-009-101. This work was also partially supported by the MOE ATU Program, Taiwan, and grant PU/CSMU-102-2 from the Chung Shan Medical University Foundation, Taiwan. Zeiss LSM 510 META confocal microscopy was performed in the Instrument Center of Chung Shan Medical University, which is supported by the National Science Council, the Ministry of Education, and Chung Shan Medical University.

\section{Disclosure}

The authors report no conflicts of interest in this work.

\section{References}

1. TsaiNM,Chen YL,LeeCC, etal. Thenatural compoundn-butylidenephthalide derived from Angelica sinensis inhibits malignant brain tumor growth in vitro and in vivo. J Neurochem. 2006;99:1251-1262.

2. Huang MH, Lin SZ, Lin PC, et al. Brain tumor senescence might be mediated by downregulation of S-phase kinase-associated protein 2 via butylidenephthalide leading to decreased cell viability. Tumour Biol. 2014; 35:4875-4884.

3. Lin PC, Lin SZ, Chen YL, et al. Butylidenephthalide suppresses human telomerase reverse transcriptase (TERT) in human glioblastomas. Ann Surg Oncol. 2011;18:3514-3527.

4. Chang LF, Lin PC, Ho LI, et al. Overexpression of the orphan receptor Nur77 and its translocation induced by $\mathrm{PCH} 4$ may inhibit malignant glioma cell growth and induce cell apoptosis. J Surg Oncol. 2011; 103:442-450.

5. Pang CY, Chiu SC, Harn HJ, Zhai WJ, Lin SZ, Yang HH. Proteomic-based identification of multiple pathways underlying n-butylidenephthalide-induced apoptosis in LNCaP human prostate cancer cells. Food Chem Toxicol. 2013;59:281-288.

6. Chiu SC, Chen SP, Huang SY, et al. Induction of apoptosis coupled to endoplasmic reticulum stress in human prostate cancer cells by n-butylidenephthalide. PLoS One. 2012;7:e33742. 
7. Liu PY, Sheu JJ, Lin PC, et al. Expression of Nur77 induced by an n-butylidenephthalide derivative promotes apoptosis and inhibits cell growth in oral squamous cell carcinoma. Invest New Drugs. 2012;30: 79-89.

8. Wei CW, Lin CC, Yu YL, et al. n-Butylidenephthalide induced apoptosis in the A549 human lung adenocarcinoma cell line by coupled downregulation of AP-2alpha and telomerase activity. Acta Pharmacol Sin. 2009;30:1297-1306.

9. Chen YL, Jian MH, Lin CC, et al. The induction of orphan nuclear receptor Nur77 expression by n-butylenephthalide as pharmaceuticals on hepatocellular carcinoma cell therapy. Mol Pharmacol. 2008;74: 1046-1058

10. Lin PC, Chen YL, Chiu SC, et al. Orphan nuclear receptor, Nurr-77 was a possible target gene of butylidenephthalide chemotherapy on glioblastoma multiform brain tumor. J Neurochem. 2008;106:1017-1026.

11. Yeh JC, Cindrova-Davies T, Belleri M, et al. The natural compound n-butylidenephthalide derived from the volatile oil of radix Angelica sinensis inhibits angiogenesis in vitro and in vivo. Angiogenesis. 2011;14: 187-197.

12. Saw CL, Wu Q, Su ZY, et al. Effects of natural phytochemicals in Angelica sinensis (Danggui) on Nrf2-mediated gene expression of phase II drug metabolizing enzymes and anti-inflammation. Biopharm Drug Dispos. 2013;34:303-311.

13. Fu RH, Hran HJ, Chu CL, et al. Lipopolysaccharide-stimulated activation of murine DC2.4 cells is attenuated by n-butylidenephthalide through suppression of the NF- $\mathrm{KB}$ pathway. Biotechnol Lett. 2011;33: 903-910.

14. Lin YL, Liu YK, Tsai NM, et al. A lipo-PEG-PEI complex for encapsulating curcumin that enhances its antitumor effects on curcumin-sensitive and curcumin-resistance cells. Nanomedicine. 2012;8:318-327.

15. Liu YK, Lin YL, Chen $\mathrm{CH}$, et al. A unique and potent protein binding nature of liposome containing polyethylenimine and polyethylene glycol: a nondisplaceable property. Biotechnol Bioeng. 2011;108:1318-1327.

16. Chen CH, Lin YL, Liu YK, et al. Liposome-based polymer complex as a novel adjuvant: enhancement of specific antibody production and isotype switch. Int J Nanomedicine. 2012;7:607-621.

17. Deng $S$, Chen SN, Yao $P$, et al. Serotonergic activity-guided phytochemical investigation of the roots of Angelica sinensis. J Nat Prod. 2006;69: 536-541.

18. Yan R, Ko NL, Li SL, Tam YK, Lin G. Pharmacokinetics and metabolism of ligustilide, a major bioactive component in rhizoma chuanxiong, in the rat. Drug Metab Dispos. 2008;36:400-408.
19. Fleury F, Kudelina I, Nabiev I. Interactions of lactone, carboxylate and self-aggregated forms of camptothecin with human and bovine serum albumins. FEBS Lett. 1997;406:151-156.

20. Burke TG, MiZ. The structural basis of camptothecin interactions with human serum albumin: impact on drug stability. J Med Chem. 1994; 37:40-46.

21. Mi Z, Burke TG. Differential interactions of camptothecin lactone and carboxylate forms with human blood components. Biochemistry. 1994;33:10325-10336.

22. Opanasopit P, Yokoyama M, Watanabe M, Kawano K, Maitani Y, Okano T. Influence of serum and albumins from different species on stability of camptothecin-loaded micelles. J Control Release. 2005; 104:313-321.

23. Opanasopit P, Ngawhirunpat T, Chaidedgumjorn A, et al. Incorporation of camptothecin into N-phthaloyl chitosan-g-mPEG self-assembly micellar system. Eur J Pharm Biopharm. 2006;64:269-276.

24. Ngawhirunpat T, Wonglertnirant N, Opanasopit P, et al. Incorporation methods for cholic acid chitosan-g-mPEG self-assembly micellar system containing camptothecin. Colloids Surf B Biointerfaces. 2009;74: 253-259.

25. Hobbs SK, Monsky WL, Yuan F, et al. Regulation of transport pathways in tumor vessels: role of tumor type and microenvironment. Proc Natl Acad Sci U S A. 1998;95:4607-4612.

26. Thurston G, McLean JW, Rizen M, et al. Cationic liposomes target angiogenic endothelial cells in tumors and chronic inflammation in mice. J Clin Invest. 1998;101:1401-1413.

27. Geletneky K, Huesing J, Rommelaere J, et al. Phase I/IIa study of intratumoral/intracerebral or intravenous/intracerebral administration of parvovirus H-1 (ParvOryx) in patients with progressive primary or recurrent glioblastoma multiforme: ParvOryx01 protocol. BMC Cancer. 2012;12:99

28. Figueiredo EG, Faria JW, Teixeira MJ. Treatment of recurrent glioblastoma with intra-arterial BCNU [1, 3-bis (2-chloroethyl)-1-nitrosourea]. Arq Neuropsiquiatr. 2010;68:778-782.

29. Carpentier A, Metellus P, Ursu R, et al. Intracerebral administration of $\mathrm{CpG}$ oligonucleotide for patients with recurrent glioblastoma: a phase II study. Neuro Oncol. 2010;12:401-408.

30. Bobo RH, Laske DW, Akbasak A, Morrison PF, Dedrick RL, Oldfield EH. Convection-enhanced delivery of macromolecules in the brain. Proc Natl Acad Sci U S A. 1994;91:2076-2080.
International Journal of Nanomedicine

\section{Publish your work in this journal}

The International Journal of Nanomedicine is an international, peerreviewed journal focusing on the application of nanotechnology in diagnostics, therapeutics, and drug delivery systems throughout the biomedical field. This journal is indexed on PubMed Central, MedLine, CAS, SciSearch ${ }^{\circledR}$, Current Contents ${ }^{\circledR} /$ Clinical Medicine,

\section{Dovepress}

Journal Citation Reports/Science Edition, EMBase, Scopus and the Elsevier Bibliographic databases. The manuscript management system is completely online and includes a very quick and fair peer-review system, which is all easy to use. Visit http://www.dovepress.com/ testimonials.php to read real quotes from published authors. 